\title{
Corrigendum: Large-scale production of megakaryocytes from human pluripotent stem cells by chemically defined forward programming
}

\author{
Thomas Moreau, Amanda L. Evans, Louella Vasquez, Marloes R. Tijssen, Ying Yan, Matthew W. Trotter, \\ Daniel Howard, Maria Colzani, Meera Arumugam, Wing Han Wu, Amanda Dalby, Riina Lampela, \\ Guenaelle Bouet, Catherine M. Hobbs, Dean C. Pask, Holly Payne, Tatyana Ponomaryov, Alexander Brill, \\ Nicole Soranzo, Willem H. Ouwehand, Roger A. Pedersen \& Cedric Ghevaert
}

Nature Communications 7:11208 doi: 10.1038/ncomms11208 (2016) Published 7 Apr 2016; Updated 28 Jul 2017

This Article contains an error in the author contributions section that has resulted in incorrect credit for preparation and critical analysis of the manuscript. The correct author contributions section is as follows:

'T.M. designed, analysed, performed and interpreted most experiments and wrote the paper. A.L.E. performed and analysed experiments. L.V. and Y.Y. performed and interpreted bioinformatics analyses pertaining to the genomic characterization of the MKs. M.R.T. contributed to megakaryocyte characterization and wrote the paper. M.W.T. performed and interpreted bioinformatics analyses pertaining to the forward programming concept. M.C. and M.A. contributed to megakaryocyte characterization. D.H., W.H.W., C.M.H., A.D., R.L., G.B. and D.C.P. performed experiments. H.P., T.P. and A.B. designed and performed intravital experiments and analysed data, A.B. also participated in preparation and critical analysis of the manuscript. N.S. interpreted bioinformatics analyses pertaining to the genomic characterization of the MKs. W.H.O. contributed platelet expert input to the forward programming concept. R.A.P. conceived the forward programming approach, designed, analysed and interpreted experiments and wrote the paper. C.G. drove the platelet biology, designed, analysed and interpreted experiments and wrote the paper.'

\footnotetext{
(c) This work is licensed under a Creative Commons Attribution 4.0 International License. The images or other third party material in this article are included in the article's Creative Commons license, unless indicated otherwise in the credit line; if the material is not included under the Creative Commons license, users will need to obtain permission from the license holder to reproduce the material. To view a copy of this license, visit http://creativecommons.org/licenses/by/4.0/
}

(C) The Author(s) 2017 